\title{
Availability Study of a Longwall Shearer Including Phases of its Operation
}

doi:10.2478/mape-2021-0018

Date of submission to the Editor: $05 / 2021$

Date of acceptance by the Editor: 06/2021

Jarosław Brodny

ORCID ID: 0000-0003-4781-8697

Silesian University of Technology, Poland

Estera Brzana

Silesian University of Technology, Poland
MAPE 2021, volume 4, issue 1, pp. 200-211

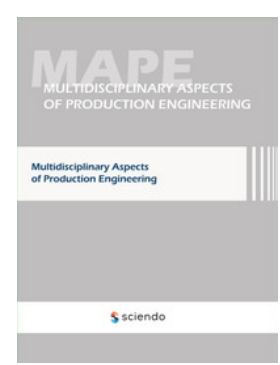

\section{INTRODUCTION}

The mining production process belongs to the group of complex production processes burdened with additional hazards due to the environment in which it is conducted. Mining production, which includes the exploitation of deposits, the horizontal and vertical transport of the output and its subsequent enrichment, uses a number of devices, especially machines. Its specificity, resulting mainly from the environment in which it is carried out, requires that these devices have additional features, rarely expected in closed processes. In underground mining production, there are a number of natural hazards which pose a great danger to the continuity and effectiveness of its implementation. Methane (Brodny and Tutak, 2019; Brodny et al. 2018; Tutak and Brodny, 2017), fire (Chen et al., 2021; Tutak and Brodny, 2019; Zhou et al., 2021), dust (Cheng et al., 2021), climatic and rock burst hazards require technical equipment and operating personnel to be properly prepared to carry out this process. Therefore, machines used in underground mining production must be of high quality and reliability, which in turn makes their costs very high. This enforces the need to make the best possible use of their potential during the production process, so that unit costs are as low as possible. Thus, the problem of effective use of machinery during mining production is very important and, in many cases, determines the sensibility of its further operation. Also, the huge competition on the energy raw materials market forces optimization activities both in terms of organization, equipment, and utilization of resources. Additionally, the process of energy and climate transformation currently taking place in the European Union (Tutak et al., 2020) makes the sustainable effectiveness of the mining production process more and more important. This particularly concerns the idea of the European Green Deal, which assumes a zero-emission EU economy by 2050 (European Commission: A European Green Deal).

These factors mean that mining production must be a highly transparent process with the least possible impact on the environment. This area obviously includes the issue of effective utilization of the machinery used in the process. 
A fundamental part of this process is mining the rock mass, which is currently carried out by mechanized longwall complexes. The longwall system allows for mining the rock mass and transporting the extracted material from the face zone, as well as securing the longwall face against deformation caused by the rock mass. The basic machine of the longwall system is a longwall shearer responsible for mining the rock mass. The technical parameters and reliability of the machine, as well as the organization of work in the longwall face, largely determine the effectiveness of the whole mining process. The high costs of a longwall shearer and its importance for the continuity and effectiveness of the process make it necessary to make the best possible use of its technical possibilities. Therefore, the aim is to create such working conditions so that the whole system works in accordance with the technical and organizational plan, being fully available during working shifts, and with planned productivity to achieve the expected quality of the output.

In this respect, the availability of the whole system, and in particular a longwall shearer, is of fundamental importance. Breaks in its operation cause the whole system to stop working, which adversely affects its effectiveness. In order to make an objective, and independent from the human factor, assessment of a longwall shearer's actual working time, a study of its availability was carried out in one of the underground hard coal mines. The analysis was based on temporal waveforms of the longwall shearer's diagnostic parameters, in the form of its velocity and position in the wall, registered by the industrial automatic system. Based on the obtained data, an analysis was made of the longwall shearer's availability, the measure of which was the ratio of its actual operation time to the standard time in which it should operate. Since the mining process in the studied mine was realized in the form of one-way mining, the analysis was performed for individual phases of the shearer's working cycle. For this form of exploitation, this cycle consists of cutting, mining, and returning (shunting movement) of a longwall shearer. For each of these phases, the time of the shearer's actual work and unscheduled stoppages were estimated and on this basis its availability during these phases was determined. This analysis is a new, previously unused approach to the study of the availability of mining machines and is aimed at indicating "bottlenecks" which reduce the effectiveness of the use of these machines.

\section{METHODOLOGY OF RESEARCH}

In order to determine the availability of the longwall shearer, the temporal waveforms of its position and feed speed recorded by the industrial automation system were used. The data were used to analyze the time of work and unscheduled breaks in this work.

The analysis was based on the TPM strategy, which is the basis for ensuring maximum efficiency of machinery and equipment (Brodny et al., 2016; Singh and Ahuja, 2014; Stecuła et al., 2017). Its aim is to make the best use of the time allocated for the production of a high-quality product and with adequate 
productivity. In order to determine the availability of the longwall shearer, the OEE model was utilized, which is a tool for assessing the effectiveness of implementing the TPM strategy. According to this model, the effectiveness of the use of machinery is measured by the Overall Equipment Effectiveness (OEE) index, which is the product of availability, productivity and quality obtained in the production process (Domingo and Aguado, 2015; Jonsson and Lesshammar, 1999; Muchiri and Pintelon; 2008; Muñoz-Villamizar et al., 2018; Tsarouhas, 2019).

The use of the OEE methodology makes it possible to determine the effectiveness of a given machine on a commonly recognized scale and to compare it with other studied objects.

In the presented case, the focus was only on the first component included in the OEE model, i.e., availability of the longwall shearer. It was assumed that in the case of the shearer in question, the other components were stable, and it was not possible to determine them with sufficient accuracy.

When studying the recorded data and the presented temporal waveforms, it can be stated that the industrial automation systems used nowadays enable very precise control of the operating condition of particular machines. However, for these data to be used in practice, it is necessary to use appropriate IT tools for their archiving, analysis and presentation of results. Industrial automation systems in combination with the tools developed and mentioned in the paper create such possibilities.

The basis of the analysis was the OEE model, which is a tool used for the quantitative evaluation of the TPM strategy (Bititci et al., 2012; Brodny et al., 2017a; Brodny et al., 2017b; Chan et al., 2004;

Domingo and Aguado, 2015; Elevli and Elevli, 2010; García-Arca et al., 2018; Jonsson and Lesshammar, 1999; Maté et al., 2017; Muchiri and Pintelon; 2008; Muñoz-Villamizar et al., 2018; Sharma, 2019; Tsarouhas, 2019).

According to this model, availability $(A)$ was determined as the ratio of the machine's operational (actual) time $\left(T_{r}\right)$ to the time the machine is available, i.e., the theoretical (normative) time $\left(T_{t}\right)$. The value of availability can be reduced by unplanned events that prevent the machine from operating. These include, in particular, breakdowns and any interruptions associated with changeovers, setup and adjustment of the machine (Nakajima, 1988; Nakajima, 1989).

The general relationship used to determine the availability of studied machines is presented in equation (1):

$$
A=\frac{T_{r}}{T_{t}}
$$

where:

$T_{r}$ - operational (actual) working time of a machine,

$T_{t}$ - theoretical (normative) working time of a machine.

For the temporal waveforms of the recorded and operationally relevant parameters obtained from the industrial automation system, the availability rate can be determined accurately. 
The actual working time of a machine $\left(T_{r}\right)$ is then the sum of the temporal waveforms $\left(T_{r i}\right)$, in which the criteria of the feed speed and current intensity consumed by the engines of these machines are met. The normative time $\left(T_{n}\right)$, on the other hand, is the known time included in the technical and organizational plan of longwall exploitation.

The use of the determined temporal waveforms allows for the calculation of the value of the availability indicator for particular machines based on the following relationship:

$$
A_{k}=\frac{\sum_{i=1}^{n} T_{r i}}{T_{n}}
$$

Equations (1-2) were used to determine the availability of the longwall shearer based on the temporal waveforms of its velocity and position in the wall.

In the presented case, the focus was on the analysis of the longwall shearer's availability with respect to particular phases of its work cycle. The longwall shearer in the mine under analysis operated in single shearer mode, which made it possible to determine its availability for particular phases of its cycle. For this purpose, its working cycles were divided into individual phases. These phases included shunting movement $(A)$, cutting (B), and mining the rock mass (C). The characteristics of these phases are shown in Table 1.

Table 1 Characteristics of different phases of the longwall shearer's work cycle

\begin{tabular}{|c|c|c|}
\hline $\begin{array}{c}\text { Phase } \\
\text { designation }\end{array}$ & Cycle phase & \multicolumn{1}{c|}{ Description of cycle phase } \\
\hline A & $\begin{array}{l}\text { Shunting } \\
\text { movement phase } \\
\text { beginning of the longwall. The movement takes } \\
\text { place with practically no load on the engines. } \\
\text { Possible "cleaning of the path" and/or support for } \\
\text { loading the output is carried out. High shearer } \\
\text { velocity. }\end{array}$ \\
\hline B & Cutting & $\begin{array}{l}\text { The process of cutting into the rock mass. The } \\
\text { goal is to set up properly for the main mining } \\
\text { operation. Several maneuvering activities - } \\
\text { different velocity and reverses. }\end{array}$ \\
\hline C & Mining the rock \\
mass & $\begin{array}{l}\text { Mining of the rock mass (mineral + possible } \\
\text { waste rock). Low velocity, full load of the longwall } \\
\text { shearer's engines. }\end{array}$ \\
\hline
\end{tabular}

Source: Own elaboration

\section{RESULTS AND DISCUSSION}

The analysis was based on diagnostic data from the operation of the longwall shearer obtained from the industrial automation system in one of the underground hard coal mines. The data in the form of temporal waveforms of the longwall shearer's velocity and its position in the longwall were the basis for determining the operating times and identification of unplanned interruptions in its work. Based on their analysis, the availability of the longwall shearer for particular phases of its operation was also determined. The analysis covered 10 cycles of the shearer's work. 
Figure 1 shows a fragment of temporal waveforms of the shearer's velocity and position for one cycle of its operation with marked phases of this cycle. The limit points for each phase are marked with points (blue filled circles) and individual phases of the cycle are marked with capital letters (A, B and C).

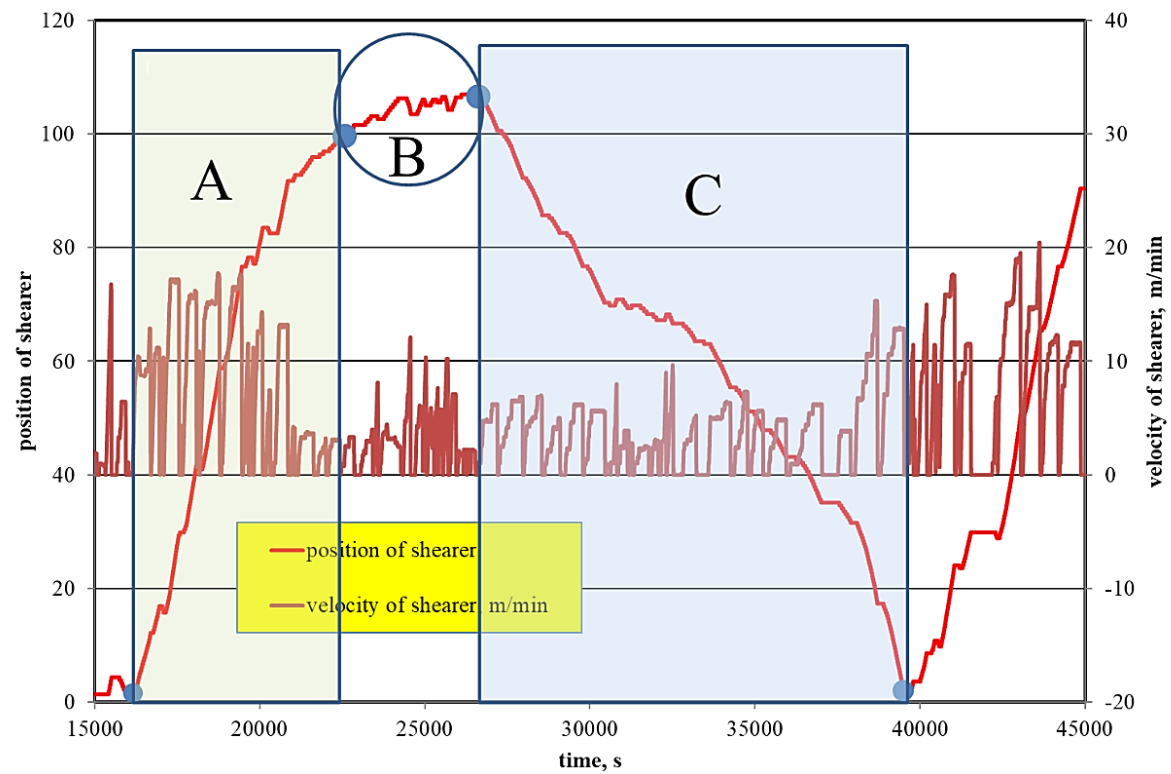

Fig. 1 Temporal waveforms of the velocity and position of the longwall shearer

Particular phases of this cycle, labeled in Figure 1 mean:

A - shunting movement phase,

$B$ - cutting phase,

$\mathrm{C}-$ mining phase.

The following figures (Fig. 2, 3 and 4) show the temporal waveforms of the shearer's velocity and position in particular phases of this cycle. Selected pauses in the shearer's operation are also marked on the Figures.

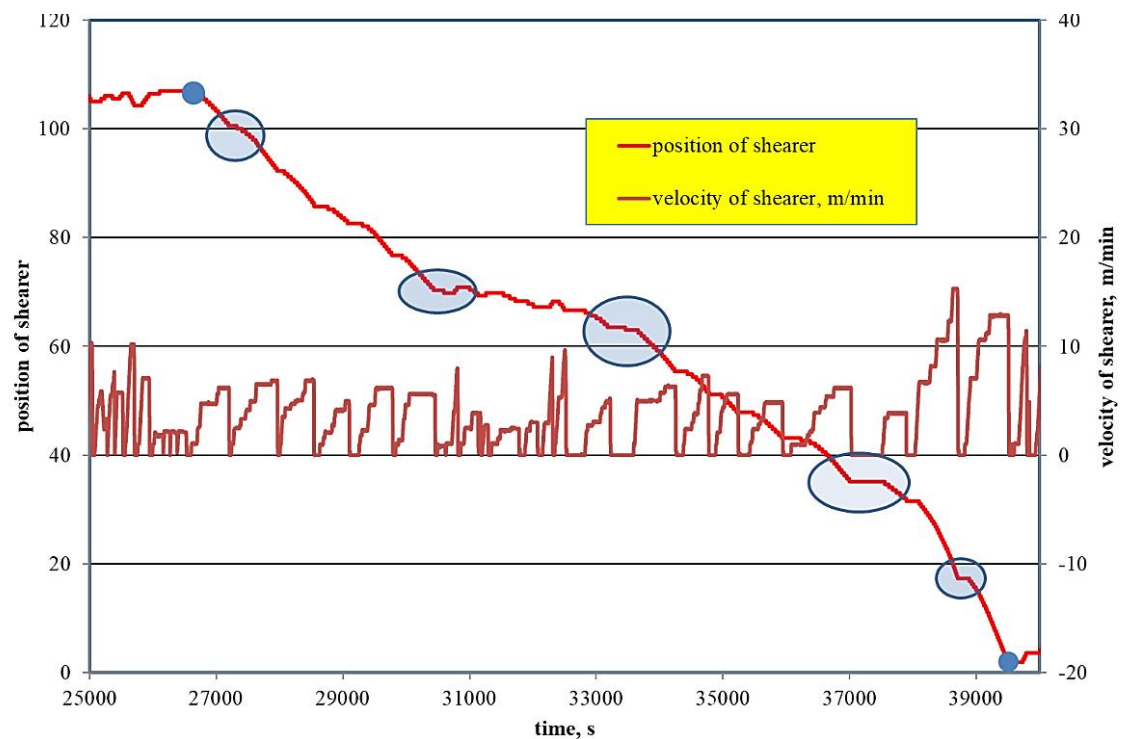

Fig. 2 Temporal waveforms of the velocity and position of the longwall shearer during the mining phase 


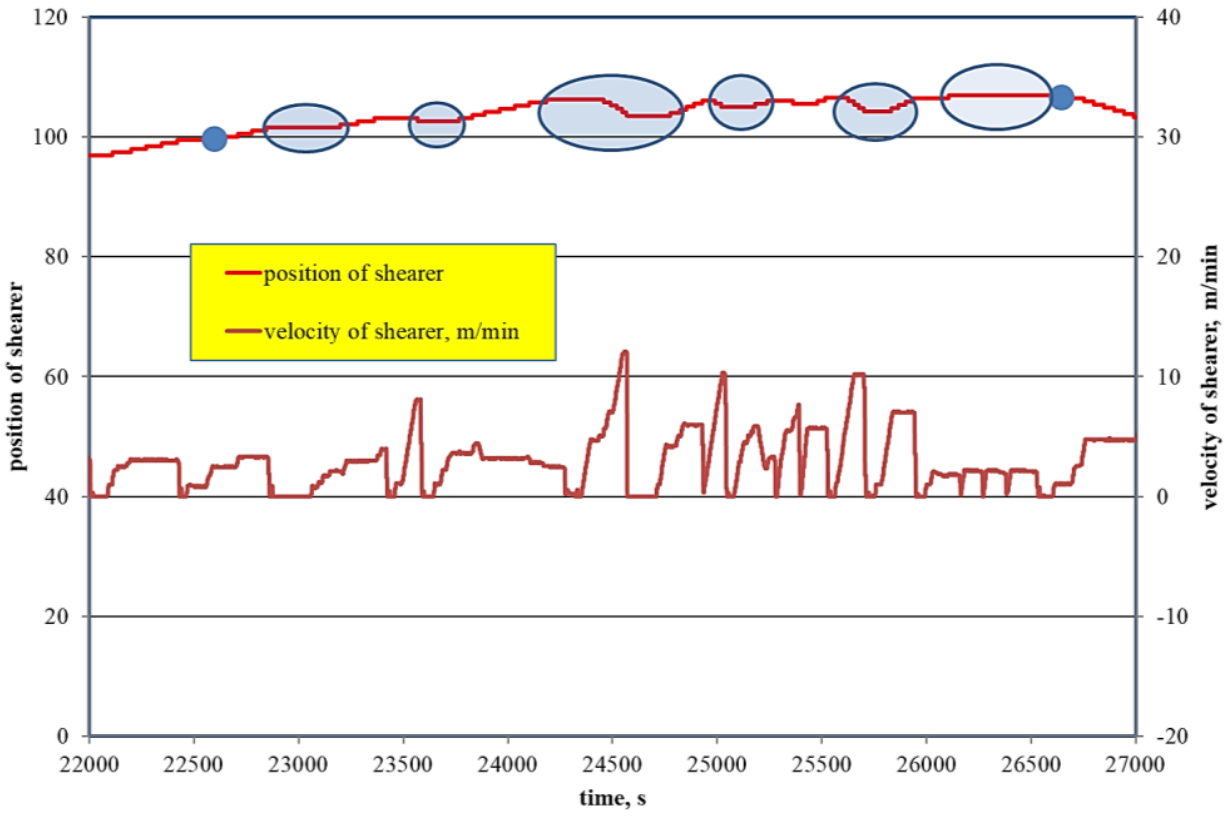

Fig. 3 Temporal waveforms of the velocity and position of the longwall shearer during the cutting phase

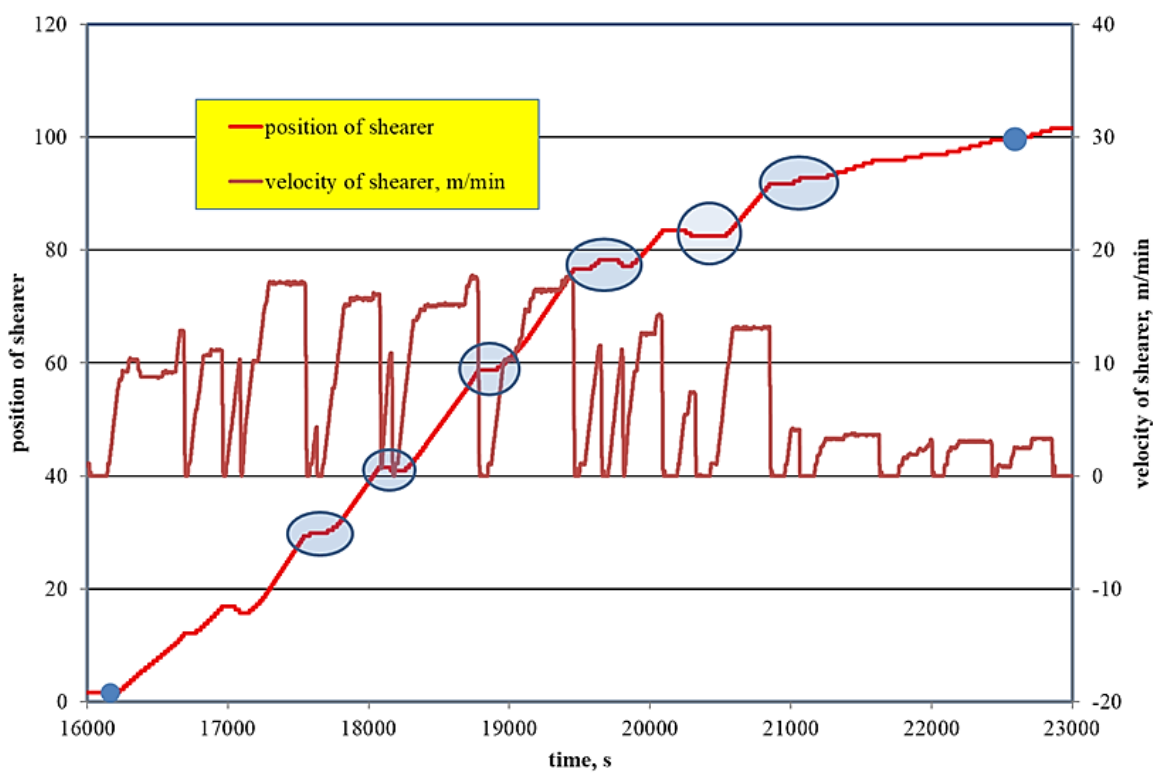

Fig. 4 Temporal waveforms of the velocity and position of the longwall shearer during the shunting movement phase

Based on the obtained waveforms, the operating times for each phase of the studied cycle and the times of unscheduled breaks, as well as the availability of the shearer for these phases were determined (Table 2). The total duration of this cycle was 5.594 seconds, i.e., over 93 minutes. The determined availability of the shearer for this cycle was $85.65 \%$, which should be considered a very good value.

The analysis of the following 9 cycles of the shearer operation (taking into account particular phases of its operation) was performed in a similar way as for the presented cycle. The results (for all 10 cycles) are presented in Table 3. 
Table 2 Summary of the longwall shearer operation parameters for the studied cycle Shearer's operating time for particular phases, $s$

\begin{tabular}{|c|c|c|c|c|}
\hline & Phase B & Phase A & Phase C & Total \\
\hline s & 1075 & 1011 & 2705 & 4791 \\
\hline \multicolumn{5}{|c|}{ Break time, s } \\
\hline s & 146 & 133 & 524 & 803 \\
\hline \multicolumn{5}{|c|}{ Share of breaks during the shearer's operation, \% } \\
\hline$\%$ & 13.58 & 13.16 & 19,37 & 16,76 \\
\hline$\%$ & 86.42 & 86.84 & 80.63 & $\mathbf{8 3 . 2 4}$ \\
\hline
\end{tabular}

Source: Own elaboration

Table 3 Summary of the longwall shearer's operation times for particular phases of the studied cycles

\begin{tabular}{|c|c|c|c|c|}
\hline \multicolumn{5}{|c|}{ Working time of shearer, s } \\
\hline Cycles & Phase A & Phase B & Phase C & Total \\
\hline 1 & 1075 & 1011 & 2705 & 4791 \\
\hline 2 & 1206 & 1227 & 2821 & 5254 \\
\hline 3 & 952 & 994 & 3200 & 5146 \\
\hline 4 & 1451 & 879 & 3230 & 5560 \\
\hline 5 & 1102 & 865 & 3020 & 4987 \\
\hline 6 & 1321 & 1100 & 2925 & 5346 \\
\hline 7 & 1435 & 1231 & 3634 & 6300 \\
\hline 8 & 1231 & 1098 & 2905 & 5234 \\
\hline 9 & 1321 & 987 & 3324 & 5632 \\
\hline 10 & 1543 & 1241 & 3647 & 6431 \\
\hline Average time & 1263.7 & 1063.3 & 3141.1 & 5468.1 \\
\hline Standard deviation & 186.28 & 139.72 & 325.49 & 533.73 \\
\hline
\end{tabular}

Source: Own elaboration

Figure 5 presents the summary of breaks for particular phases of the shearer's work cycles.

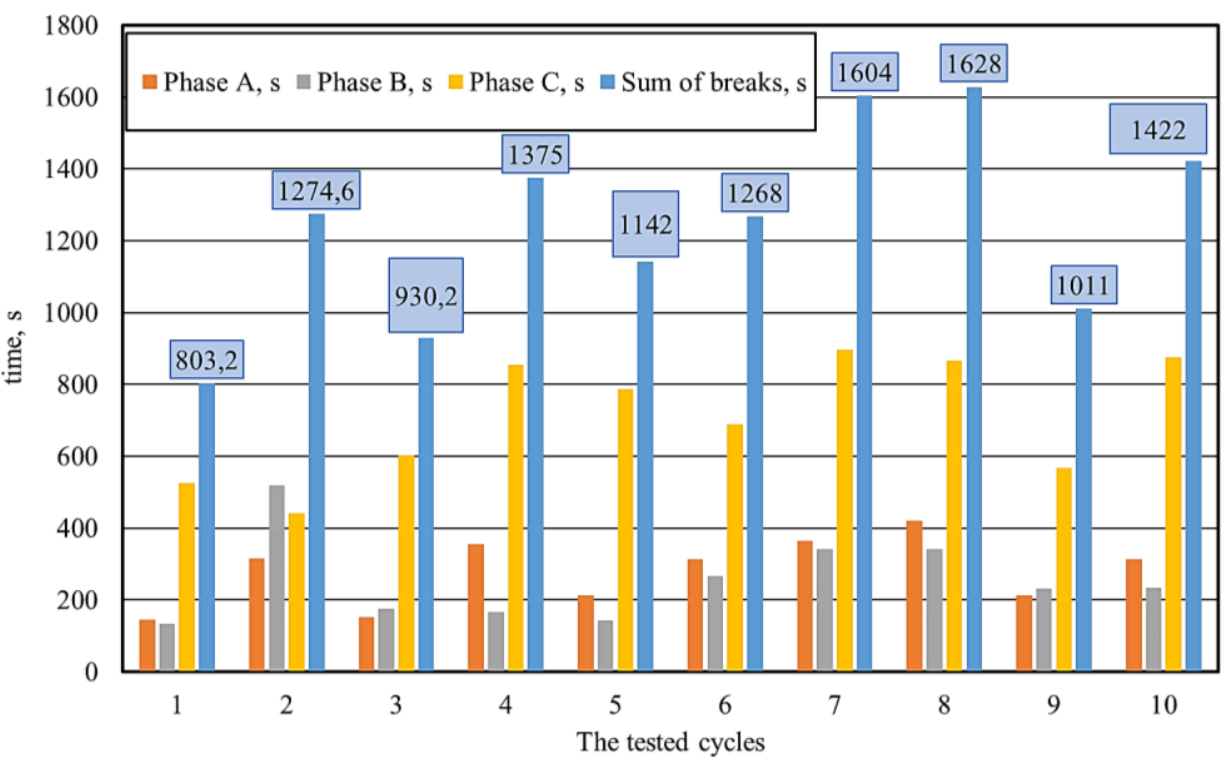

Fig. 5 Summary of breaks for particular phases of the longwall shearer's operation cycles 
The percentage share of breaks during particular phases of the studied cycles of the shearer's work is presented in Figure 6.

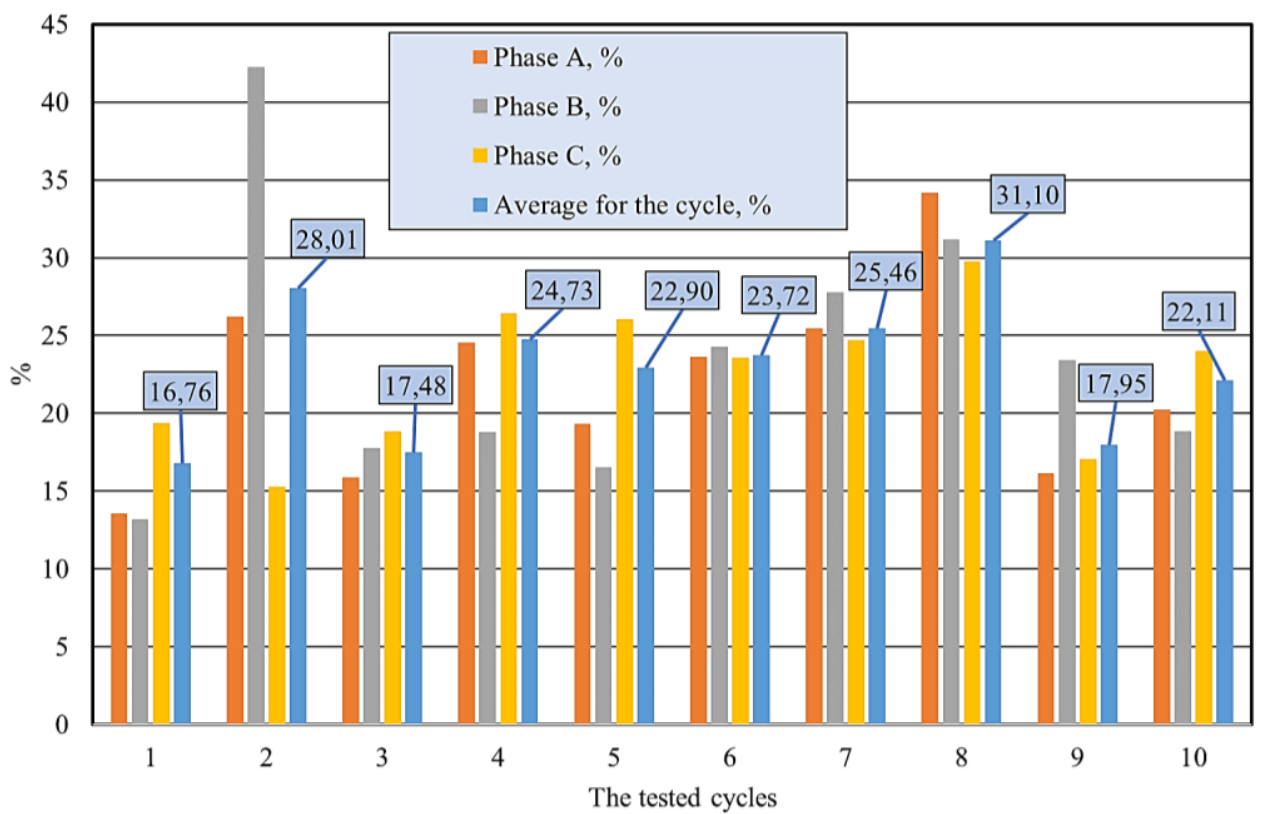

Fig. 6 Percentage share of breaks for particular phases of the longwall shearer's operation cycles

Based on the performed analyses, the availability of the longwall shearer for the studied cycles and their phases were determined. The results are presented in Table 4.

Table 4 Comparison of the longwall shearer's availability for particular phases of the studied cycles

\begin{tabular}{|c|c|c|c|c|}
\hline \multicolumn{5}{|c|}{ Shearer's availability, \% } \\
\hline Cycles & Phase A & Phase B & Phase C & For the entire cycle \\
\hline 1 & 86.46 & 86.83 & 80.61 & 83.24 \\
\hline 2 & 73.82 & 57.76 & 84.74 & 71.99 \\
\hline 3 & 84.12 & 82.27 & 81.16 & 82.52 \\
\hline 4 & 75.47 & 81.23 & 73.56 & 75.27 \\
\hline 5 & 80.67 & 83.47 & 73.97 & 77.10 \\
\hline 6 & 76.38 & 75.73 & 76.44 & 76.28 \\
\hline 7 & 74.56 & 72.22 & 75.32 & 74.54 \\
\hline 8 & 65.80 & 68.85 & 70.22 & 68.90 \\
\hline 9 & 83.88 & 76.60 & 82.94 & 82.05 \\
\hline 10 & 79.78 & 81.14 & 75.98 & 77.89 \\
\hline Average value & 78.09 & 76.61 & 77.50 & 76.98 \\
\hline Standard deviation & 6.15 & 8.57 & 4.65 & 4.67 \\
\hline
\end{tabular}

Source: Own elaboration

A graphical representation of the results is presented in Figure 7. It defines the availability of the shearer for particular studied cycles. 


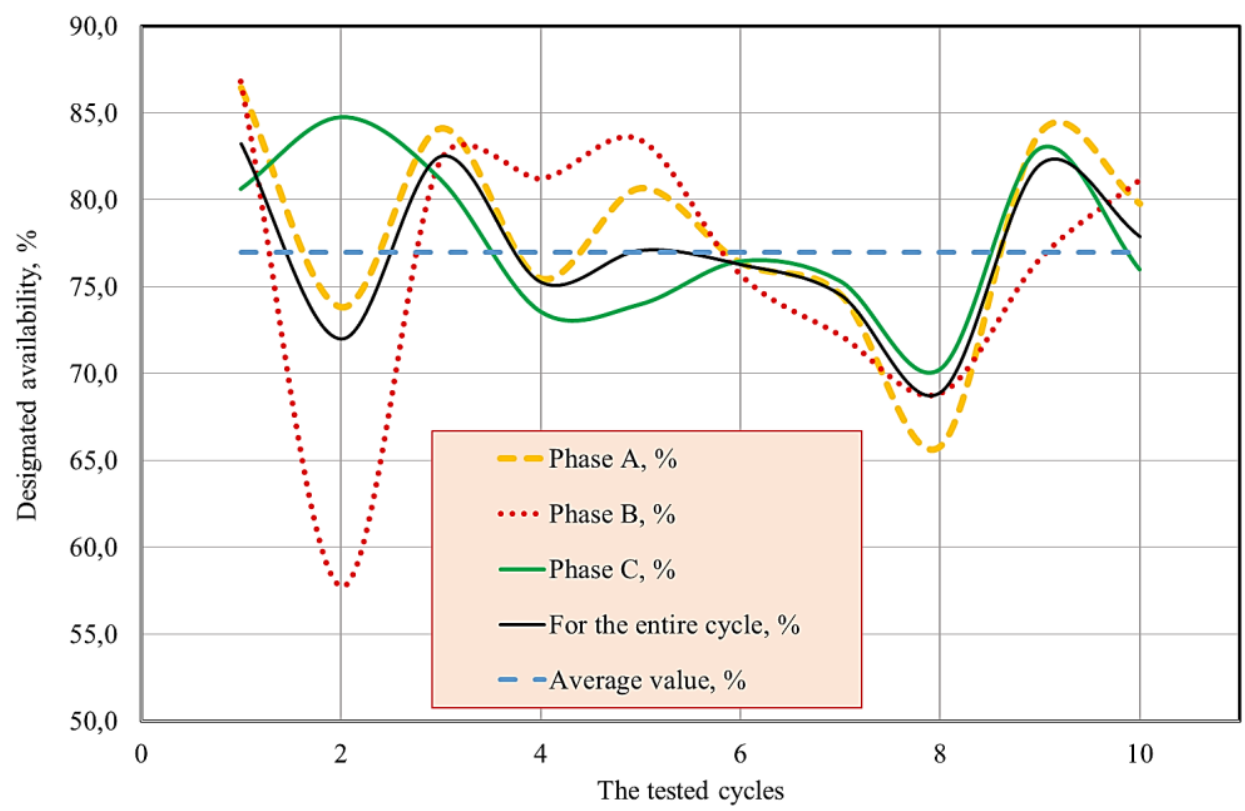

Fig. 7 Summary of the longwall shearer's availability in particular phases of the studied cycles

\section{CONCLUSION}

The paper deals with an immensely important and current problem, which is the study of accessibility of mining machines. In the case of longwall shearers, which are part of the mechanized mining complex, accessibility is the basis for determining the effectiveness of their work. In the case under study, reference is made to the availability of the longwall shearer, as the basic machine mining the rock mass and operating in the single-sided mining mode. The longwall shearer operates in cycles comprising mining, returning, and cutting. As these phases differ significantly in terms of the nature of work, the analysis of availability was carried out with reference to these phases.

The analysis was based on diagnostic signals obtained from the industrial automation system. Based on the temporal waveforms of the shearer's velocity and its position in the exploitation wall, its availability was determined for particular studied cycles and their phases. The applied data acquisition system has proven to be very reliable and objective, and independent of the subjective feelings of employees. This helped determine the actual shearer's availability in the studied period and relate it to particular phases of its operation.

The results unequivocally confirmed that the availability of the longwall shearer, and thus of other machines in the longwall system, is not the highest. The average value for the longwall in question was almost $77 \%$, which should be considered an acceptable result. It should also be noted that in the period in question, no dangerous phenomena related to the working environment or machine breakdowns were recorded. In this context, the results could have been higher.

However, the analysis of the shearer's availability in particular phases of its operation clearly indicates that the lowest availability and the greatest variation 
in it was recorded in the cutting phase. Such a result seems logical, since a number of complex processes take place in this phase in order to prepare properly for the mining phase. However, the temporal waveforms of this phase are the smallest in the whole cycle, which means that their influence on the availability for the whole cycle is relatively small. Nevertheless, it was quite surprising to find out that the shearer's availability in the shunting (return) phase was relatively low. The availability for this phase was reported to be similar to that for the other phases, despite the fact that from the point of view of the mining process the shearer was least loaded in this phase. However, in the analyzed period, a lot of unplanned interruptions in the shearer's work were recorded in this phase.

The results showed that further action should be taken to identify the causes of unplanned interruptions in the operation of machines in particular phases of their work cycle. These causes should be identified for the return or shunting phase of the shearer. Limiting the time of these breaks should considerably improve the availability of the shearer and the other machines of the complex. This, in turn, should translate into improved availability of these machines and effectiveness of the whole mining process.

\section{ACKNOWLEDGEMENTS}

The research presented in the paper was supported by statutory work BK273/ROZ3/2021 carried out at the Chair of Production Engineering, Faculty of Organization and Management, Silesian University of Technology.

This article is the result of the research project No. PBS3/B6/25/2015 "Application of the Overall Equipment Effectiveness method to improve the effectiveness of the mechanized longwall systems' work in the coal exploitation process" realized in 2015-2018, financed by NCBiR.

\section{REFERENCES}

Brodny J., Stecuła K., Tutak, M. (2016). Application of the TPM strategy to analyze the effectiveness of using a set of mining machines. 16th International Multidisciplinary Scientific GeoConference SGEM2016. SGEM2016 Conference Proceedings, Book 1, Vol. 2, pp. 65-72.

Brodny J., Tutak, M. (2019).Forecasting the distribution of methane concentration levels in mine headings by means of model-based tests and in-situ measurements. Archives of Control Sciences, 29 (1), pp. 25-39.

Brodny J., Tutak M., John A. (2018). The impact of airway geometry on the distribution of methane concentrations at the outlet from a longwall. Mechanika, 24(5), pp. 695-702.

Chen X., Feng S., Wang L., Jia Q. (2021). Distribution and Prevention of CO in a Goaf of a Working Face with Y-Type Ventilation. ACS Omega, 6(3), pp. 1787-1796.

Cheng J., Zheng X., Lei Y., Luo W., Wang Y., Borowski M., LiX., Song W., Wang Z., Wang K. (2021). A compound binder of coal dust wetting and suppression for coal pile. Process Safety and Environmental Protection, 147, pp. 92-102.

Domingo R., Aguado S. (2015). Overall Environmental Equipment Effectiveness as a Metric of a Lean and Green Manufacturing System. Sustainability, 7, pp. 90319047. 
Elevli S., Elevli B. (2010). Performance Measurement of Mining Equipments by Utilizing OEE. Acta Montanistica Slovaca, 15, pp. 95-101.

European Commission: A European Green Deal (2019) [online]. Available at: https://ec.europa.eu/info/strategy/priorities-2019-2024/european-green-deal_en (accessed on 11 January 2021).

García-Arca J., Prado-Prado J.C., Fernández-González A.J. (2018). Integrating KPIs for improving efficiency in road transport. Int. J. Phys. Distrib. Logist. Manag., 48, pp. 931-951.

Jonsson P., Lesshammar M. (1999). Evaluation and improvement of manufacturing performance measurement systems. The role of OEE. Int. J. Oper. Prod. Manag., 19, pp. 55-78.

Maté A., Trujillo J., Mylopoulos J. (2017). Specification and derivation of key performance indicators for business analytics: A semantic approach. Data Knowl. Eng., 108, pp. 30-49.

Muchiri P., Pintelon L. (2008). Performance measurement using overall equipment effectiveness (OEE): Literature review and practical application discussion. Int. J. Prod. Res., 46, pp. 3517-3535.

Muñoz-Villamizar A., Santos J., Montoya-Torres J., Jaca C. (2018). Using OEE to evaluate the effectiveness of urban freight transportation systems: A case study. Int. J. Prod. Econ., 197, pp. 232-242.

Nakajima S. (1988). Introduction to TPM. Total Productive Maintenance. Productivity. Press, Portland.

Nakajima S. (1989). TPM development program. Productivity Press, Cambridge.

Sharma R. (2019). Overall equipment effectiveness measurement of TPM manager model machines in flexible manufacturing environment: A case study of automobile sector. Int. J. Product. Qual. Manag., 26, pp. 206-222.

Singh K., Ahujal.P.S. (2014). Assessing the business performance measurements for transfusion of TQM and TPM initiatives in the Indian manufacturing industry. Int. J. Technol. Policy Manag., 14, 44.

Stecuła K., Tutak M., Brodny J. (2017). Application of chosen elements from Japanese production and maintenance management philosophies in Polish coal mines. International Multidisciplinary Scientific GeoConference Surveying Geology and Mining Ecology Management, SGEMVolume 17, Issue 13, 2017, pp. 93-100. $17^{\text {th }}$ International Multidisciplinary Scientific Geoconference, SGEM 2017; Albena; Bulgaria; 29 June 2017-5 July 2017.

Tutak M., Brodny J. (2017). Analysis of influence of goaf sealing from tailgate on the methane concentration at the outlet from the longwall. IOP Conf. Ser., 95, 042025.

Tutak M., Brodny J. (2019). The Impact of the Strength of Roof Rocks on the Extent of the Zone with a High Risk of Spontaneous Coal Combustion for Fully Powered Longwalls Ventilated with the Y-Type System. A Case Study. Appl. Sci. 9, 5315.

Tutak M., Brodny J., Siwiec D., Ulewicz R., Bindzár P. (2020). Studying the Level of Sustainable Energy Development of the European Union Countries and Their Similarity Based on the Economic and Demographic Potential. Energies 13, 6643.

Zhuo H., Qin B., Qin Q. (2021). The impact of surface air leakage on coal spontaneous combustion hazardous zone in gob of shallow coal seams: A case study of Bulianta Mine, China. Fuel, 295,120636. 
Abstract: The mining production process includes a number of sub-processes, the most important of which is mining the rock mass. In this process, increasingly modern mining machines are being used to replace human labor and to achieve high productivity. Full utilization of the potential of these machines is of great importance for the efficiency of individual stages and the whole process of mining production. In the process of mining the rock mass, the use of machinery of a mechanized longwall system is of fundamental significance. Their availability, efficiency and reliability significantly affect the efficiency of the whole mining production process. The paper refers to the availability of a longwall shearer as the basic machine of a mechanized mining system. Based on the analysis of diagnostic signals, recorded by the industrial automation system, the availability of the longwall shearer was determined for 10 selected cycles of its operation. The analysis also included the phases of these cycles, treated as separate periods of the shearer's work. This division is a consequence of a great difference in the character of the shearer's work in particular phases of the operating cycle. The analysis covered the phases of cutting, mining and shunting. The determined temporal waveforms and the shearer's availability in these phases show their great diversity. Therefore, the results indicated the necessity to analyze the operation of mining machines in their characteristic periods, which can be the basis for minimizing unplanned interruptions in their operation and improving the efficiency of their use.

Keywords: mining machines, efficiency, machine availability, OEE, industrial automation 